\title{
SEVERAL PURPOSES WITH ONE COURSE - THE CHALLENGE OF TEACHING TERMINOLOGY AS PART OF A PRACTICAL TRANSLATOR TRAINING PROGRAMME
}

\begin{abstract}
Within the field of Translation Studies, terminology plays an important role, as does the study of Terminology. This paper investigates the possibilities available within the constraints of a single course aiming to achieve multiple aims. A brief overview of how terminology is studied is followed by a presentation of the context, looking at the position of the course in relation to other courses in the same programme, and at the broader context of Translation Studies in Europe. The case study is of a Terminology course, as part of a post-graduate, two-semester, parttime programme in Translation, at Kodolányi János University of Applied Sciences in Hungary. The question of why terminology has a course to itself is likewise placed in the context of Terminology Studies and theoretical issues related to what terminology is. Finally, the course is also placed within the context of training students to become professionals in translation and related fields.
\end{abstract}

Keywords: terminology, translation training, higher education, technical vocabulary, transferable skills, curriculum

Słowa kluczowe: terminologia, kształcenie tłumaczy, szkolnictwo wyższe, terminologia fachowa, uniwersalne umiejętności, program nauczania 


\section{Introduction}

Within the field of Translation Studies, terminology plays in important role, as does the study of Terminology. This paper investigates how various aims can be fruitfully targeted with a single course. In what follows, two strands are examined: the academic strand focusing on the study of Terminology and the pedagogic strand focusing on what can be taught and learnt in one languageoriented course in terminology. The case study is of a Terminology course, which forms an integral part of a post-graduate, two-semester, part-time programme in Translation, offered in Budapest, Hungary, by Kodolányi János University of Applied Sciences.

On the one hand, the position of the course in relation to other courses in the same programme, and in the broader context of Translation Studies in Europe is, presented, as is the approach to the teaching of the course content. On the other hand, the pertinent question of why terminology has a course to itself is discussed against the backdrop of a brief introduction to Terminology Studies and theoretical issues related to what terminology is. Finally, the course is also placed within the context of training students to become professionals in translation and related fields. Beyond introducing the students to the field of terminology and developing their knowledge of the terminology related to their specialisation, the course offers them the opportunity of dealing with challenging texts and acquaints them with ways of approaching these challenges.

\section{Theoretical background to the study of terminology}

From the perspective of the practising translator, a large majority of documents (including business and commercial texts) today are produced as specialist communication and are thus written in the language used by specialists. The degree to which specialist language is composed of terminology (including non-linguistic items) is dependent on the domain and on the type of text, but it is typically significant. It follows that the quality of specialist communication is dependent on the quality of the terminology used. Appropriate and accurate use of terminology contributes to effective communication, increasing clarity and reducing ambiguity or vagueness. (POINTER Final Report, 1997) Clearly, any writer using technical terms or specialised languages has to be proficient in the use of the relevant terminology. This is doubly true for translators, as any weaknesses of usage in the source text or the translation are compounded by the need in translation to use terminology across languages. 
Several purposes with one course - the challenge of teaching terminology...

\subsection{Brief overview of terminology as a field of study}

As a field of study, terminology is relevant to both linguistics and the domain of the individual subject area. It can be approached as the systematised concepts of a specific subject area or as the designations themselves. As an academic discipline, Terminology supports effective knowledge representation and transfer. The field owes a great debt to the seminal work of Wüster (see Wüster, 1979), who promoted the view that a concept is universal and independent of cultural differences, and was a strong advocate of standardisation which he saw as a way of eliminating ambiguity from technical languages. As an engineer schooled in languages but not a student of formal linguistics, Wüster himself represented a professional approach rather than a linguistic orientation (Antia, Budin, Picht, Rogers, Schmitz \& Wright, 2005). After many years as the dominant General Theory of Terminology, or Vienna School (based on Wüster's approach), critiques of Wüster's ideas and contradictions between principles and real data have led to innovative theoretical initiatives (see Budin, 2001, Cabré Castellvi, 2003). Amongst others, Cabré (1999 and 2003) advocates for a Communicative Theory of Terminology, Temmerman $(1997,2007)$ favours a sociocognitive approach, whilst Faber Benitez (2009) proposes Frame-based Terminology.

The pervasiveness of indeterminacy, which has been underscored in the past half century, has been researched focusing on all three aspects of the traditional semiotic triangle, namely, concept, object and symbol as related to the mind, the world and the language. Indeterminacy highlights the danger of trying to achieve a one-to-one view of translational lexical relations and helps to clarify some aspects of terminology management systems which need to follow the principle of term autonomy (as a consequence of synonymy) and the principle of concept orientation (as a consequence of homonymy), in both monolingual and multilingual data models (Budin et al., 2006). There is, at present, a lively debate going on about whether there is a theory of terminology, whether Terminology is a discipline, and what an improved or new theory of terminology is or could be. The ideal classical concept, with necessary and sufficient conditions and clear-cut boundaries, denoted by one term only (and therefore only one term for a concept) has become contentious; prototypically structured categories present features such as polysemy, synonymy, and figurative language, and methods and structures have to be found to incorporate these in meaning description (Temmermans, 2001, Zawada \& Swanepoel, 1994). Over time it has become clear that the phenomena of variation and evolution need to be dealt with. Variation can occur vertically, due to the existence of various, differing registers, or horizontally within one register, due to various, differing expressive purposes 
or preferences (Peruzzo, 2013). Peruzzo adds that the evolution of a knowledge domain can also lead to diachronic changes in terminology.

Temmerman (2007) explores the possibility of alternative approaches to traditional Terminology. Rather than starting from the concept, language can be seen as a means for conceiving categories and communicating about them. Furthermore, categories are fuzzy, that is they cannot be "absolutely classified by logical and ontological means" (Temmerman, 2007: 29). Variability occurs and polysemy, synonymy and figurative language can be functional, contributing to coherence and text cohesion (Temmerman 2007, after Collet 2005). Furthermore, categories are not fixed, they evolve over time with ensuing changes in meaning.

\subsection{Discipline specific examples}

All of this has extensive consequences in the day-to-day use of terminology. To take an example from close to home, let us consider a qualitative analysis of a random selection of problematic terms in translation research collected by Pym (Pasin, Delgao \& Fischer, 2015, after Pym, 2011) The authors investigated 15 terms, analysing their ambiguity. Other than the case where the "Term fits perfectly", all the other criteria indicated polysemy, synonymy, evolution, variation depending on collocation or being a misnomer, or having fallen into disuse (Pasin et al., 2015: 34). At the heart of translation studies, terminology is concerned with "compiling, describing, processing and presenting" the terms of specialised subject areas (Pasin et al., 2015: 33) and yet the field itself indicates the limitations of the Wüsterian ideal of unambiguous, standardised terms.

Questioning the applicability of univocity underlies the discussion in Chiocchetii and Ralli (2009) of the difficulties of drafting terminological definitions for legal terms, what legal definitions are and how legal terms should be defined. The authors point out that there is no common understanding of what definitions should be and that definitions vary. However, there seems to be more agreement as to their purpose, which is seen as placing a term within a system and specifying what delimits it from other terms in a communication situation. In the field of the law, definitions are important for the reduction of vagueness and ambiguity. Nevertheless, legal terms need to fit within a legal system and are subject to interpretation. These qualities are in fact functional, in that they allow the further development of the law. They are context-dependent, and the context can determine how a term is to be interpreted. Chiocchetii and Ralli (2009) investigate the structure and form of definitions of legal terms by analysing examples from a multilingual terminological data bank and they conclude that a generally valid model for terminological definitions is unlikely to be developed since the situation and the purpose determine the way terms are described. Furthermore, it is significant to 
note that their analyses look at the German versions of the definitions. A similar analysis of these terms across several languages would show the multiplier effect of differences in language, in context, in legal systems and of the placement of the legal terms within a system. All this serves to support the need for alternatives to the Wüsterian approach.

Terminology work need not necessarily be carried out with translators in mind. If it is, then the specific requirements of translators must be an integral part of the process and contribute to a functional and reliable outcome. With this thought we can move on to approach the topic of this paper from a different angle by shifting to the context of the translator training course in the focus of our case study. First of all, the institution itself will be introduced. This will be followed by a presentation of the translator training programme for "Translator in Economics and Social Sciences" (referred to in what follows as "TTP-Ec\&SocSc")

\section{The institution and the programme}

Kodolányi János University of Applied Sciences (KJUAS) is a foundation university in Hungary with state accreditation and campuses in Budapest, Szekesferhévár and Orosháza. It offers a range of academic programmes in the fields of tourism and hospitality, business management, mass media and communication, social sciences and history, as well as the language and cultural studies relevant to this paper. The translator training programme for "Translator in Economics and Social Sciences" (TTP-Ec\&SocSc) has been offered since 2005, originally in both Szekesferhévár and Budapest, but currently only in Budapest. The programme duration is two semesters and it is offered part-time (60 credits, 90 contact periods/semester). As this is a post-graduate programme, the latter point is important for many of the students, who are likely to be employed, or at home on maternity benefits. Over time, the particulars of what courses are offered, the number of contact hours and the pedagogical details have been modified in line with market expectations - both on the side of potential employers and on the side of potential students - and in line with trends and developments Europe-wide in the area of translator training. On the other hand, the pedagogical approach has remained constant: KJUAS is committed to being a centre of excellence, with highly qualified staff dedicated to helping the students become competent professionals.

\subsection{Need for and value of the TTP-Ec\&SocSc}

With regard to the positioning of the translator programme: the translation industry is interesting in that a qualification from an institution of higher education 
is not in all cases a prerequisite for practising as a translator. It is, however, an advantage, especially for newcomers to the field. In the OPTIMALE employer survey (covering representatives of the very diverse European translation industry), a relevant university degree in translation or related areas was amongst the most important competences classified as being essential or important, with the support of $77 \%$. There was general consensus that the quality of the translator is decisive for the quality of translations, however, "Whether this should be achieved by academic translator training programmes, by experience and in-house training within translation service providers, by continuing professional development or by a combination of all three, was a moot point discussed in a number of workshops" (OPTIMALE Progress Report: Public Part, 2012: 17). Beyond the informed debate on this topic, local solutions to the issue of requirements are varied. In Hungary, self-employed specialised translators can take an accreditation exam (offered nationwide by ELTE-FTT) without taking part in a course, whilst a diploma from an accredited course serves a similar purpose.

The general title of "translator" is - in line with common practice throughout Europe - still unprotected (Pym, 2009). This, coupled with the fact that certification is not essential, puts the onus on institutions and accreditation examination providers to promote the professional standing of the translators they endorse. Indeed, the status of translators continues to be in a state of flux, with modifications of regulations nationally (for example, as regards taxation or provision of authorised translations), the proliferation of associations (for translators, agencies, language service providers, academics), and translator-client on-line portals. For Terminology courses, this sets the task of sampling the existing vocabulary knowledge of the students and insisting on their giving evidence of minimum standards; as offering them opportunity under guided circumstances to improve their knowledge, and as providing direction for continuous, life-long maintenance and further learning.

\subsection{Situation as regards KJUAS}

The courses offered at KJUAS for the TTP are in line with the general approach common in Europe since the first schools of translation/interpreting were founded in Heidelberg (1930), Geneva (1941) and Vienna (1943), stressing the traditions of master-apprentice instruction and institutionalised training (Pym, 2009). Degree programmes in foreign languages often include translation courses, partly as a continuation of the traditional pedagogical approach using translation as a way of checking language acquisition and grammatical/lexical knowledge, and partly as a way of meeting societal needs for translators. The 
trend, however, has been to offer independent training programmes for translators, with two versions dominating: a long-term model with extensive language (often more than one foreign language), culture and communication training as its core and a specialisation phase in the final years; and more intensive, Master's level programmes that are often more skills-based, or offer specialisations (Pym, 2009). The KJUAS programme is in this stream, but - as a consequence of the particular way in which the Bologna process was implemented in Hungary - it is a not a fully-fledged Masters, but a post-graduate diploma requiring a Bachelor's degree (or higher, of course) for admission. As is the case in most of the states of the ex-Soviet bloc, translation in both directions is required. KJUAS offers the course with one foreign language, with students having the choice of English or German. Their existing degree can be in any discipline. As the focus of the programme is on Business Studies and Social Sciences, applicants tend to self-select: engineers and natural scientists tend not to apply, although students have come to us with backgrounds in information technology, or food sciences. The usual group includes a large proportion of language or business-related graduates, with varying degrees of work experience. Although no prior experience of translating is required, the course does attract many practising translators who would like to broaden their perspectives or need a formal qualification for some reason. Interestingly enough, the requirements do not actually specify a level of language proficiency. On the output side, the final diploma is legally considered to be the equivalent of a complex specialised CEFR C1 language proficiency certificate. Prior work experience is not recognised and a placement period or internship is not included. In all aspects, these characteristics fall within the normal range of what is offered in Europe (based on information collected, collated and analysed by OPTIMALE, see Gambier, 2013, Valeró-Garcés, 2013).

It is clear from the above that admission to the programme is based on the individual's self-assessment in several ways. This entails an obligation for level checks within the programme and a strictly applied, criterion-based evaluation of ability at the end. At KJUAS, the final examination consists of two parts: a written 4-hour translation examination with an English (or German) to Hungarian and a Hungarian to English (or German) component; and a degree paper. (The situation in Europe according to the OPTIMALE research was somewhat hard to interpret: 39 of 91 programmes have such a requirement, 32 stated they did not and 20 did not mention it - indicating an ambiguity in the framing of the question. (Gambier, 2013)). The degree paper as required by KJUAS, which has to be defended viva voce, consists of two translations, with introductory commentaries (related to text, audience analysis and context), and also a commentary on challenges and difficulties presented by the 
translations, a glossary (identifying the source and allowing for further commentary) and a set of examples of translational transfer operations, according to the typology developed by Klaudy (2003). The guiding principle here is that the degree paper comprises not only the product, i.e. the actual translations that are evaluated, but demonstrates the student's insight into translation issues and problems, processes and strategies. Thus, for example, the glossary is a compilation of source terms and also other lexical items with definitions. The lexical items are linked to their co-text, which is itself placed in context in the pre-analysis, whilst the source that the translator found reliable needs to be specified for the definitions, and comments, such as why the particular source was chosen, what other choices were considered, what the challenge presented was, or whether usage had changed over time are allowed/encouraged. The descriptor-based evaluation criteria for the degree paper and the examination translations are:

- use of language,

- style, register,

- fidelity,

- coherence,

- use of terminology, and

- grammatical accuracy.

The examiner functions in two roles as reader: on the one hand as a simulated member of the target audience and, on the other hand, as a professional, considering the various aspects of the translation. The mark is a combination of a global mark and an analytical mark based on the criteria. The exam translations and degree papers are both marked by two independent markers. The need for both forms of evaluation is justified by the differing challenges presented by the exam and the writing of the degree paper. In the latter case, the situation is close to real life, with the students able to work according to their own habitus and habits, with the same resources and settings available to them that they would have in executing professional commissions. These include their own opportunities to reflect, consult and revise, as well as their own access to specialised sources, be they human, virtual, or paper-based. They can dedicate as much time as they wish to this process and benefit from the guidance of and feedback from their supervisor and class-mates. In the exam, the conditions are levelled, with all students subject to the same physical conditions (exam hall, strange computer, temperature and noise in the room) and time constraints. This is a more artificial environment, and the task itself is unusual in that the source text is short, the time available to access parallel texts and to revise is limited, and there is a need to translate in both language directions within a short 
time span. The two approaches contribute to making the evaluation process overall as even-handed as possible - individual differences, preferences and limitations will tend to balance each other out.

\subsubsection{The programme}

This brings us to the curriculum for the programme of studies. Once again using the OPTIMALE analyses as point of reference (Valero-Garcés, 2013), the KJUAS programme does not have a cultural or linguistic focus but does include courses in CAT tools (Trados and MemoQ in particular). Although these cannot be considered in-depth, they are supported by other courses incorporating aspects of ICT. Together with the other practical translation courses, these form the overwhelming majority of the programme. In previous versions, when more contact hours were required, the language/linguistic, cultural and areas studies aspects received more focused attention. Of these, it is only Terminology and Introduction to the Theory and Practice of Translation courses that have been retained. Including a theoretical aspect is a subject of debate, with professional translators often complaining that formal, academic training programmes are too academic, or are too theoretical (Pym, 2009). Pym adds that a theoretical component remains frequent, with varying content. In our view, higher education is progressively being perceived as being about professional excellence and preparing students for later professional life; however, the fundamental objective of enquiry and research must not be lost sight of. Students can make practical use of their knowledge of what is understood as translation theory in a wider sense, but may also find their curiosity awakened and even choose to study further and/or engage in research (Richter, 2008).

In part-time courses, the onus is on the students to complement their existing knowledge - whether related to language, culture, technology or domain - as needed, whilst it is the responsibility of the teachers to guide them in this endeavour, taking into account the very mixed levels of knowledge, which also vary in terms of point of focus. For example, the graduates of language programmes will have prior knowledge of linguistics, a major advantage for the theoretical content, whilst the graduates of courses related to business will have an advantage in terms of their understanding of business processes, issues and terms. The domain area (and by implication some cultural content) is covered extensively in the task-and text-based translation classes and is further targeted with the electives, which vary, but almost always include a course on the European Union. In view of the above, the challenges and opportunities presented by the course on Terminology will be considered, focusing on the overt and covert aims and objectives, as well as how these are targeted in practice. 


\section{Why a course in terminology should be included}

Teaching terminology, in the sense of specialised vocabulary or an inventory of terms, may seem an obvious requirement, but it is worth asking why we offer such a course in a compact, practice-oriented, two-semester part-time course. Other options, from the ethics of translation, through courses on language or culture, to a course (sometimes offered as an elective) on professional practice, all compete for inclusion. The guiding principle of economic use of time and resources requires that this question be answered. Part of the solution lies in the incorporation of multiple purposes in the terminology course, as indicated in the title of this paper. Some of these purposes can only be touched upon, but their inclusion is important as a point of orientation for the students, who get to see aspects of the field that may have escaped their notice. In what follows, T/terminology, (both spelt with lower case and with an upper-case initial letter), will be examined and related to the need for it being taught in the TTP-Ec\&SocSc.

The theoretical aspects discussed above are less directly relevant for those students who already are, or who are going to become, commercial translators of specialised texts. Some of them, however, may be attracted to academic inquiry into translation. In line with industry and employer's expectations, the trend in translation studies has been towards the development of transferable skills in addition to skills related to translation (Horbačauskiené, Kasperavičiené \& Saulé, 2017). Academics do, however, deal with the identification and explanation of problems related to professional communication and practitioners do benefit from the applied aspect of their work. And there may be those amongst the students who are drawn to the study of Terminology, or to a career as a terminologist.

\subsection{The case for a course in terminology}

To return to the original question, terminology has its place in our translation training programme because our graduates will need to produce texts in specialist language, based on a generally accepted level of prior knowledge (linguistic, socio-cultural and domain-related), recognising terminological challenges when they occur, and able to apply the appropriate strategies/use the available resources needed to resolve their difficulties in their particular communicative situation.

As such, the course provides an excellent opportunity for adding information on topics related to terminology and translation (as mentioned above), as well as multi-faceted opportunities to ascertain whether the background knowledge and training of the students are adequate for their future practice. It is not possible and is not necessary to actually fill knowledge or 
skill gaps as it is enough for students to know what it is that they have to pay attention to, and to give pointers on how to acquire what is missing. A mindset of awareness and a schema for accessing whatever needs to be supplemented can be actively developed in the course. Furthermore, there is clearly a case for training terminologists, just as there is a case for developing terminological resources and infrastructure within a system of adequate information and efficient administration. Opportunities for making students aware of these potential career paths arise naturally in a terminology course. The same is true for academic research directions, or even teaching careers.

'Prior knowledge' can cover an almost infinitely wide range if we consider both business studies and social sciences. Furthermore, there is the cultural knowledge associated with the target audience, since language goes beyond exchanging information and expressing cultural reality, it creates socially shared realities. Primarily, the requirement of prior knowledge refers to the cultures associated with the languages, bearing in mind that this may cover multiple languages and multiple (sub-)cultures. Accepting Kramsch's (1998) understanding of culture as "membership in a discourse community that shares a common social space and history, and common imaginings", specifying further that "Even after they have left that community, its members may retain a common system of standards for perceiving, believing, evaluating and acting" (Kramsch, 1998: 10), the case of English is unusually complex. The default requirement would be a knowledge of British or American Studies, but the cultures of other anglophone areas of the world are likewise relevant, whether they are what could be called peripheral standards (such as Canadian or Australian English) or New Englishes. Indeed, the English spoken as a lingua franca or language of international communication can be seen to have its own cultural background. Furthermore, the occupational cultures of the business world (finance, production, marketing, logistics and so on) are likely to be pertinent.

The degree to which such needs can be met in any particular programme is dependent on various factors, not the least of which are time and competing, even conflicting, needs. Suggestions for what should be covered with what level of importance attributed to it - in a fully-fledged course on terminology are rather hard to find, but a well-thought-out and comprehensive programme dealing with the role of terminology in the translation process, and including both theoretical and practical aspects, is outlined by Martinez and Faber (2009) in their article on terminological competence in translation. The KJUAS programme allocates 6 contact classes, spread over 2 semesters. These are exploited to the full to allow for many seemingly disparate purposes to be included. In the past few semesters, a two-pronged approach has evolved: the actual classes are dedicated to tasks, discussions and 'theorising' about terms 
and terminology, as well as testing, whilst the periods of intensive autonomous studying are spent learning the words they need to know and use.

\subsubsection{Raising students' awareness}

Given the complexity of Terminology, in a brief course it is unrealistic to do more than raise students' appreciation of the issues and sensitise them to the need for realistic expectations. The course is directly practice-oriented, therefore, the primary need is to ensure fluent comprehension and use of the appropriate level of terminology (and the associated general English expressions, style and register) within the subject-domain. As indicated above, the KJUAS programme offers specialisation in Business Studies and Social Sciences. In the field of business studies, a proficiency standard has, therefore, to be set, opportunities to reach that standard given, and tested. For this, a selection of the excellent Business English books (CEFR level C1) available on the market is used, and the students are expected to reach the set standard largely based on autonomous study at home. The tests serve not only to document their abilities, but also as feedback. On the input side, the level of proficiency is very mixed and the two semesters allow sufficient time for the playing field to be levelled - for some this is a stretch objective, for others, it is an opportunity to revise existing knowledge. As far as the social sciences are concerned, they immediately confront us with an unachievable teaching objective: each of the social sciences has its own terms, indeed branches and individual schools of thought within the social sciences may and do have their own sets of terms. The best that can be done with regard to the social sciences, therefore, it to treat the field of business studies and its associated terminology in such a way that the students have a model that they can use as a way of setting about recognising, researching and using the terms that appear in the texts from the social sciences that they translate. Time in the contact classes is allocated to discussing two crucial questions:

(1) "What does it mean to not understand a text?" An answer is sought through looking at texts which the students find hard to understand and dealing with grammatical, lexical and extra-linguistic factors.

(2) "What does it mean to know a word?" To answer this question, the students embark on a journey of self-reflection and find out that the following are all relevant: register, meaning, formation, etymology, connotations, pronunciation, spelling, grammatical patterns of use, collocations, frequency and domain. These approaches to both challenging texts and to investigating words from diverse perspectives can be seen as transferable skills that they will be able to continue using in the future. 


\subsubsection{Generic and specific transferable skills}

A short digression here will clarify what is meant by 'transferable skills' and why these are important when we consider how best to teach translation. Traditionally, they referred loosely to those mostly positively viewed skills complementing academic knowledge that are learnt in the course of studying at a university and then applied to employment. As the environment in which we live and work becomes more global, more multicultural, and integrative of a wide range of technological tools, the need for such skills has been increasingly recognised and there has been considerable discussion of the value of overtly teaching them. For higher education objectives, the emphasis has generally shifted progressively from academic competence to operational competence. The value of adaptability has risen with the perception that it is likely that graduates will be expected to change roles within their careers and that their career opportunities are likely to be impacted by fast and fundamental changes beyond their control. The expectation, on the part of both students and employers, is that graduates will be able to make an immediate contribution on being hired, and this expectation includes both subject-related competence and (inter-)personal skills. Research has looked at employers' expectations (see for example, Diamond, Walkley, Forbes, Hughes \& Sheen, 2011; Bennett, 2002 or the British Council's study on the topic, 2011), and it has become clear that higher education has a responsibility in this regard. In Jones (2013), the focus is on internationalisation and two categories are considered. The list, we suggest, resonates with our expectations for our graduates (Jones, 2013: 8):

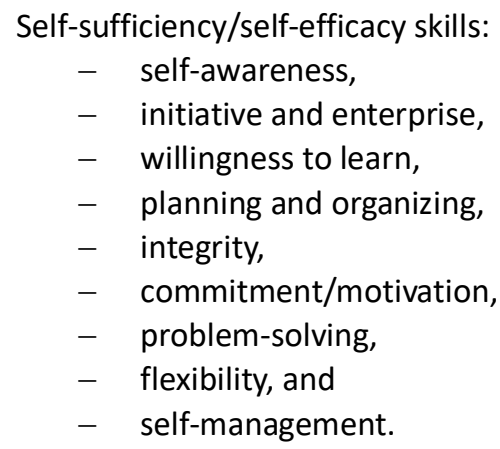

People skills:

- team working,

- communication skills,

- foreign language,

- networking,

- leadership, 
- customer service,

- interpersonal skill, and

- intercultural skills.

Research specific to the translation industry and the institutions of higher education teaching it has also been undertaken. Horbačauskienè (2017) placed her study in the context of official documents which prescribe quality standards (European Quality Standard for Translation Services EN-15038 (2006), European Reference Framework for a Master's in Translation (EMT) (2009) and Translation Services - Requirements for Translation Services ISO 17100 (2015)). From these, she identifies and specifies the five different competences required: translating competence, linguistic and textual competence, research competence, cultural competence and technical competence. The transferable skills which employers (both agencies and large companies with in-house translators) considered important were: creativity in problemsolving, lifelong learning, responsibility for performance results, independent work skills, skills of teamwork, effective communication skills, assessment and planning of necessary resources, ability to use databases, skill in computeraided programs and skills of file formatting (Horbačauskienè, 2017: 154-155). Some of these bear the characteristics of the profession (in particular, the technical skills associated with ICT); whilst some reflect a change in the way translators work (the rise in the importance of teamwork and communication). So beyond generic personal and inter-personal skills, there is also a need for the development of discipline-specific professional employability skills.

At KJUAS there is course time devoted to using ICT and also a dedicated course for CAT tools (we introduce the students to Trados and MemoQ). These courses complement the course in Terminology, moving some content that could be included there into a separate focal point. Within the course, the aim of increasing their actual knowledge of business studies-related terms is put into a framework in which they develop functional modus operandi for identifying, researching and using technical terms in the course of translating. This is done through text-based tasks. The texts, which are specifically chosen to provide comprehension challenges, also include ones related to the social sciences of the students' choice, depending on their actual interests and background.

While translating, one of the challenges is to recognise when a technical term is being used and to treat it as such. Robinson (2003), in his book suggesting ways of approaching translation theory and practice, introduces the idea of the "shuttle" (drawing on the work of Charles Sanders Peirce), that is, the process in which translators move between novel situations and more "habitual' ones, where they can work subliminally. Translators are most effective 
when they shuttle appropriately between fast, 'subliminal', flow-like processing and conscious, analytical experience, aroused by some trigger signalling the need for full awareness. The hard to pin down sensitivity to recognising that something needs to be investigated is one of the long-term characteristics of a good translator. Without it, experienced and self-confident translators can find out that a solution to a recurrent translation dilemma that they have been applying for years without questioning it, is flawed. A similar sensitivity needs to develop for a translator to recognise that a word which is common in general English is used in a way that suggests it is a technical term. The situation where the term is unknown to the translator in simpler. In this case, the alarm bells ring immediately. Good translators are those who are able, in a way consistent with their experience, to switch to conscious mode, what Kahneman (2011) calls "slow thinking" or "System 2 thinking", which is slow, more reasonable and analytical, and requires deliberate cognitive effort, to check or research the word in question.

Teaching and learning could be aided by being able to reliably identify technical terms. Chung and Nation (2004) look at and compare four approaches. One way of identifying terms in a text which has become prevalent is by using term extraction software. This works best when it is conducted on a large technical text with a non-technical corpus or text for comparison, as technical terms are those that are found mostly in technical texts. Dictionaries and terminological databases are based on specialists choosing the terms they include. Another way of accessing specialist knowledge is within texts themselves, where the writer of the text may provide information about what should be seen as a technical term, for example by labelling drawings or figures, overt definitions and by use of typographical signals, such as boldface or italics. The fourth approach is using a rating scale based on the judgement of reliable raters, who are experts able to indicate how closely words are related to a particular subject area and other associated terms. Chung and Nation set out to find the "reliable, valid and practical approach" with the intention of providing support for a number of endeavours, including teaching and development of further resources (Chung, Nation, 2004: 262). The incorporation of such research into the development of reference works and teaching materials can help the learners and facilitate teaching of technical vocabulary in the translation studies classroom, as well as other learners of English for Specific Purposes.

\section{Conclusion}

In the KJUAS Translator Training Programme in Economics and Social Sciences, and in particular in the Terminology course, students have time and guidance 
to reflect on the language mediation process, leading naturally to the realization that in order to effectively translate specialized texts, a translator must be aware of how to identify and resolve terminology problems, in addition to having a suitable knowledge base of subject-relevant terms and a broad and accurate command of the languages concerned. This paper has described in some detail the aims and assumptions of the Terminology course and how it fits into the TTP-Ec\&SocSc programme, which is in turn aligned with other European translator training programmes. Within the course itself, theory and practice come together for the benefit of the students, and - albeit indirectly - for the benefit of the users of translations.

\section{REFERENCES}

Antia, B. E., Budin, G., Picht, H., Rogers, M., Schmitz, K.-D., Wright, S. E., Clas, A. (2005), Shaping translation: A view from terminology research (in) "Meta", No 50(4).

Bennett, R. (2002), Employers' demands for personal transferable skills in graduates: A content analysis of 1000 job advertisements and an associated empirical study (in) "Journal of Vocational Education and Training", No 54(4), 457-476, DOI: 10.1080/13636820200200209.

British Council/Think Global (2011), The global skills gap: Preparing young people for the new global economy. (London) https://think-global.org.uk/wp..cont ent/uploads/dea/documents/BusinessPoll_online_TG.pdf.

Budin, G. (2001), A critical evaluation of the state-of-the-art of terminology theory. "ITTF Journal", No 12(1-2), pp. 7-23.

Cabré s, M.T. (2003) Theories of terminology - Their description, prescription and explanation (in) "Terminology", No 9(2), pp. 163-199. https://doi.org/10.1 075/term.9.2.03cab.

Cabré, M.T. (1999), Terminology: Theory, Methods and Applications. Amsterdam/John Benjamins.

Chiocchetii, E., Ralli, N. (2009), Definition und Definierbarkeit des Rechtbegriffs in der Terminologie (in) VAKKI Symposium XXIX, "Language and power", No 36. Vaasa: Unieristy of Vaasa, pp. 98-109. http://www.vakki.net/publicatio ns/2009/VAKKI2009_Chiocchetti\&Ralli.pdf.

Diamond, A., Walkley, L., Forbes, P., Hughes, T., Sheen, J. (2011), Global graduates into global leaders. London: CIHE.

Faber Benítez, P. (2009), The cognitive shift in terminology and specialized translation. Universidad de Alicante: Servicio de Publicaciones. 
Gambier, Y. (2013, June), Cartographie succincte des programmes de traduction. University of Turku, Finland. Paper presented at the Final Conference of OPTIMALE. University of Rennes.

Horbačauskienė Jolita. (2017), Translation studies: Translator training vs employers' expectations (in) "Journal of Language and Cultural Education", No 5(1), pp. 145-159 DOI: https://doi.org/10.1515/jolace-2017-0009.

Jones, E. (2013), Internationalization and employability: The role of intercultural experiences in the development of transferable skills (in) "Public Money and Management", No 33(2), pp. 95-104. https://www.academia.edu/2489954/ Internationalization_and_employability_the_role_of_intercultural_experie nces_in_the_development_of_transferable_skills.

Kahneman, D. (2011), Thinking, fast and slow. London: Allen Lane.

Klaudy, K. (2003), Languages in translation: Lectures on the theory, teaching and practice of translation; with illustrations in English, French, German, Russian and Hungarian. Budapest: Scholastica.

Kramsch, C. (1998), Language and Culture. Oxford: Oxford University Press Martínez, S.M., Faber, P. (2009), Terminological Competence (in) “Translation. Terminology" No 15(1), pp. 88-104. <http://dx.doi.org/10.1075/term.15.1.05mon. OPTIMALE Optimising Professional Translator Training in a Multilingual Europe (2012), Progress report: Public part. http://www.ressources.univ-rennes2.f r/service-relations-internationales/optimale/attachments/article/40/Publ ic\%20part_report_2010_OPTIMALE\%204018-001-001.pdf

Pasin, D., Delgado, H., Fischer, V. (2015), Dealing with ambiguity: An analysis of Pym's recommendations to retrieve ambiguities of terms related to translation studies (in) "International Journal of Language and Linguistics", No 2(8), pp. 33-40.

Peruzzo, K. (2013), Short-period evolution in EU legal texts: Old and new terms, old and new concepts (in) "Linguistica", No 53(2), pp. 39-53. https://www.d lib.si/stream/URN:NBN:SI:DOC-9CYCYX1K/1b1afe78-1e98-4e88-95ee-3a1 8b75898eb/PDF.

POINTER (Proposals for an operational infrastructure for terminology in Europe) Final Report. (1997), http://www.computing.surrey.ac.uk/ai/pointer/report/

Pym, A. (2009), Translator Training. Pre-print text written for The Oxford Companion to Translation Studies. https://www.researchgate.net/publicati on/242711915_Translator_training.

Pym, A., Grin, F. Sfreddo, C., Chan, A.L.J. (2012, June), The Status of the Translation Profession in the European Union: (DGT/2011/TST): final report, 26 June 2012. Luxembourg: Publications Office of the European Union. https://ec.europa.eu/info/departments/translation. 
Richter, B. (2008), Practical and Theoretical Elements of Translator Training in Hungary: A Case Study (in) "Studia universitas Babes-Bolyai philologia" No 53(3), pp. 67-80.

Robinson, D. (2003), Becoming a translator: An introduction to the theory and practice of translation. London: Routledge.

Temmerman, R. (2007), Approaches to terminology. Now that the dust has settled (in) Simonnæs, I. (ed.), SYNAPS 20. Bergen: NHH, pp. 27-36.

Temmerman, Rita (1997), Questioning the univocity ideal: The difference between socio-cognitive Terminology and traditional Terminology (in) "Hermes", No 18, pp. 51-90. https://www.semanticscholar.org/paper/Rita-Temmerman _*-Questioning-the-univocity-ideal---Temmerman/e6312c9d1efeff3a609c d6819c52844d41f303e2.

Valero-Garcés, C. (2013, June), Mapping Translator Training in Europe. Presentation at the Final Conference of OPTIMALE at the University of Rennes.

Wüster, E. (1979), Einführung in die allgemeine Terminologielehre und terminologische Lexikographie. Teil 1-2. Springer-Verlag. 